\title{
Comparison of different native barley varieties using an in vitro gas production technique using rumen fluid from fistulated and from slaughtered sheep as inocula
}

E Parand, A Taghizadeh

University of Tabriz, Tabriz, East Azarbyjan, Islamic Republic of Iran

Email: ehsanparand@gmail.com

Introduction Different barley varieties have been shown to affect in vitro dry-matter digestibility (IVDMD), ruminal starch digestion and animal performance (Boss and Bowman, 1996). Some of these differences may be due to differences in site and extent of nutrient digestion among barley varieties. Little information is available on digestive characteristics of different barley varieties and several native varieties are cultivated in eastern Azerbaijan province, Iran. An in vitro gas production technique was used to evaluate the effects of barley variety on gas production characteristics of barley grain. The treatments compared were 1) Sahand barley, 2) Abidar barley, 3) Sararud barley, and 4) Qarah barley. Also this study was carried out to compare the use of slaughtered sheep's rumen fluid as the source of microbial enzyme for the gas production technique with that of rumen fluid collected from fistulated sheep .

Material and methods Rumen fluid was provided by two fistulated sheep ( $2 \mathrm{~h}$ after the morning feed), fed twice daily with alfalfa hay $(400 \mathrm{~g} / \mathrm{kg})$ plus commercial sheep concentrate $(600 \mathrm{~g} / \mathrm{kg})$. Different barley varieties were collected from several farms in the eastern Azerbaijan province, Iran. For the second method, rumen contents were removed from two healthy sheep immediately after their slaughter. Both rumen fluid collected from fistulates and from slaughtered animals were strained through four layers of cheesecloth before use. Gas production was measured using the method of Fedorak and Hrudey (1983). Triplicate ground and dried samples of each barley variety (approximately 300mg) were weighed and placed in $50 \mathrm{ml}$ capacity serum bottles; then bottles were incubated in $20 \mathrm{ml}$ of buffered rumen fluid (buffer: rumen fluid, $2: 1, \mathrm{v} / \mathrm{v}$ ) for $48 \mathrm{~h}$. Gas production was recorded at 2, 4, 6, 8, 12, 16, 24, 36 and $48 \mathrm{~h}$ of incubation. The data at the different times was analysed using completely randomised design.

Results Results showed that gas producton volume was greatest for the Sahand barley and lowest from the Qarah barley (Table 1). No significant difference between Abider and Sararud varieties was observed. There was a relationship between in vitro gas production volume $(\mathrm{ml} / \mathrm{g} \mathrm{DM})$, using fistulate rumen fluid $(\mathrm{x})$, and in vitro gas production volume (ml/g DM) using slaughtered animal's rumen fluid (y) at different time intervals which suggests that rumen fluid from slaughtered animals can be used successfully for evaluating concentrate feedstuffs with the gas production technique (Table 2).

Table 1 Effect of barley variety on in vitro gas production with fistulated sheep's rumen fluid (ml/g DM).

\begin{tabular}{llllll}
\hline \hline \multirow{2}{*}{ Time } & Barley varieties & & & & \\
\cline { 2 - 6 } & Sahand & Qarah & Sararud & Abidar \\
\hline $2 \mathrm{~h}$ & $27.5^{\mathrm{ab}}$ & $23.6^{\mathrm{b}}$ & $26.6^{\mathrm{ab}}$ & $30.3^{\mathrm{a}}$ & 0.94 \\
$12 \mathrm{~h}$ & $79.9^{\mathrm{a}}$ & $66.5^{\mathrm{b}}$ & $74.4^{\mathrm{ab}}$ & $81.8^{\mathrm{a}}$ & 1.82 \\
$24 \mathrm{~h}$ & $184.5^{\mathrm{a}}$ & $175.4^{\mathrm{d}}$ & $178.3^{\mathrm{c}}$ & $180.7^{\mathrm{b}}$ & 1.92 \\
$48 \mathrm{~h}$ & $206.5^{\mathrm{a}}$ & $198.2^{\mathrm{c}}$ & $203.1^{\mathrm{b}}$ & $203.2^{\mathrm{b}}$ & 1.33 \\
\hline \hline
\end{tabular}

Means in the same row with different letters (a, b, c, d) differ $(\mathrm{P}<0.05)$.

Table 2 The relationship (simple $\mathrm{x}$, y regression) between in vitro gas production volume (ml/g DM), using rumen fluid (x), and in vitro gas production volume ( $\mathrm{ml} / \mathrm{g} \mathrm{DM})$ using faecal fluid (y) in different time intervals.

\begin{tabular}{lll}
\hline \hline \multirow{2}{*}{ Varieties } & \multicolumn{2}{l}{ Incubation time } \\
\cline { 2 - 3 } & 2h-48h & $2 \mathrm{~h}, 12 \mathrm{~h}, 24 \mathrm{~h}$, and $48 \mathrm{~h}$ \\
\cline { 2 - 3 } & Variance accounted for $\left(\mathrm{r}^{2}\right)$ & \\
\hline Sahand & 0.92 & 0.88 \\
Qarah & 0.96 & 0.94 \\
Sararud & 0.96 & 0.93 \\
Abidar & 0.95 & 0.93 \\
\hline \hline
\end{tabular}

Conclusions Our results showed that there is a significant difference between barley varieties in in vitro gas production and they have different starch degradation characteristics. These differences may be important since barley is a source of rapidly degradable starch in the rumen and lower amounts of it would lead to decreased production level, while an excess of rapidly digestible starch may increase incidence of disorders such as acidosis or bloat. In addition, our results suggest that rumen fluid from slaughtered animals can be used to evaluate concentrate feedstuffs in the in vitro gas production technique, thus eliminating the need for fistulated animals, and possibly reducing the costs of the method. The total gas production volume obtained using by slaughtered animal's rumen fluid was is higher than that obtained from fistulate rumen fluid and so mathematical correction might be needed.

\section{References}

Boss, D. L. and J.G.P. Bowman. 1996. Journal of Animal Science 74, 1973-1981.

Fedorak, P M and Hrudey, S.E. 1983. Environmental Technolgy Letters. 4, 425-432.

McDougall, E.I. 1948. Biochemistry Journal 43, 99-109. 